\title{
Development of Cheap LM35-Based Air-Conditional Automation System
}

\author{
Oyelakin Kazeem Akinloye \\ Department of Physics, Federal University of Technology, Akure, Nigeria
}

\section{Email address:}

oyelakin13@yahoo.com

\section{To cite this article:}

Oyelakin Kazeem Akinloye. Development of Cheap LM35-Based Air-Conditional Automation System. American Journal of Management Science and Engineering. Vol. 2, No. 5, 2017, pp. 156-159. doi: 10.11648/j.ajmse.20170205.20

Received: April 17, 2017; Accepted: June 12, 2017; Published: October 24, 2017

\begin{abstract}
Convenience, Comfort and Conservation are three undeniable products of Home Automation and Smart Home benefits. To this end, this work aimed to design, construct and implement a Cheap Air Conditional (AC) Automation System that schedules automatically when it should be ON or OFF based on the prevailing ambient temperature. Methods of Electrical/Electronic design and constructions were employed. The Sensor and Switching units were separately designed, constructed using electronic components and tested before and after casing. This system helps in making switching AC convenient for home owners/occupants by removing manual switching and at the same time improving comfort. Another benefit of this system is its ability to conserve energy by automatically switching off the AC when it senses it should not be on. It was evident - from the result- that this system can sense/detect the ambient temperature and switch on/off the AC.
\end{abstract}

Keywords: Automation, Air-Conditional, Temperature, Sensor, Convenience

\section{Introduction}

Imagining a summer without Air-Conditioner (AC) is like seeing in your mind's eye a world without Global System for Mobile communications (GSM). There were certainly other ways by which people try to outsmart the weather before Willis Carrier's invention came to the rescue at the dawn of the 20th century. During a third-century summer, the eccentric Roman Emperor Elagabalus sent 1,000 slaves to the mountains to fetch snow for his gardens. And, fans - be they electric gadgets or palm leaves wielded by servants helped create their share of faux wind. But it was AC that truly signified the onset of man-made weather by both cooling air and controlling humidity.

Early home automation began with labor-saving machines. Self-contained electric or gas powered home appliances became viable in the 1900s with the introduction of electric power distribution [1] and led to the introduction of washing machines (1904), water heaters (1889), refrigerators, sewing machines, dishwashers, and clothes dryers.

Home automation or smart home is the residential extension of building automation and involves the control and automation of lighting, Heating (such as smart thermostats ), Ventilation, Air-Conditioning (HVAC) and security, as well as home appliances such as washer/dryers, ovens or refrigerators/freezers that use $\mathrm{WiFi}$ for remote monitoring. Heating, Air-Conditioning and Refrigeration (HACR) is Similar to HVAC, which is the technology of indoor and vehicular environmental comfort.

Modern systems generally consist of switches and sensors connected to a central hub sometimes called a "gateway" from which the system is controlled with a user interface that is interacted either with a wall-mounted terminal, mobile phone software, tablet computer or a web interface, often but not always via internet cloud services.

Many authors have proposed different types of home automation systems of diverse complexities and capabilities. Marimuthu et. al (2006) discussed control of device using Bluetooth and internet/wired. [2]

Another Bluetooth-based home automation paper was authored by Piyare and Tazil (2011) where a Bluetooth based home automation system using cell phone was proposed which focuses on the design and implementation of a low cost, flexible and wireless solution to the home automation. [3]

While, Naresh et. al (2013) in their paper titled Bluetooth 
Based Home Automation and Security System Using ARM7 proposed an home automation system which describes the approach to control various home appliances with ARM7 processor. [4]

Rana and Singh (2014). worked on the design and implementation of an ATmega-Based embedded system which can easily interface with the existing home appliances and communicate with smart phone via Bluetooth using serial interfacing. [5]

Another work by Pandya et. al (2016) proposed an

Android Based Home Automation System Using Bluetooth and Voice Command with Internet of Thing (IoT) an home automation system that uses Bluetooth for interaction between the android mobile application and the appliances under the control of the system. [6]

All these works and more are very attractive but for the shortcomings of their complexities and ease of adaptation and implementation and replication. And, majority of these systems are not designed to start home appliances automatically based on ambient condition without input from occupants. Hence, the need for a more simpler, adaptable Automation System that can be easily implemented and replicated.

But for the exception of wealthy few, all these are far beyond the reach of the general populace - for their unaffordability - who also desire to enjoy the benefits of automations, as all animals are presumed to be equal. Hence, the need for the Development of Cheap Air-Conditional Automation System that is affordable and adoptable by the common people. This system that must perform equal function as the ones designed for the affluents with reduced maintenance cost is the focus of this paper.

Heating, ventilation and air conditioning (HVAC): it is possible to have remote control of all home energy monitors over the internet incorporating a simple and friendly user interface [7].

Appliance control and integration with the smart grid and a smart meter, taking advantage, for instance, of high solar panel output in the middle of the day to run washing machines [8-9].

Microsoft Research found in 2011, that home automation could involve high cost of ownership, inflexibility of interconnected devices, and poor manageability [10]. Keeping your cooling system running efficiently, saving on energy consumption, preventing it from overworking have always been a problem.

Prices of these high end smart devices are usually beyond the reach of common people; this, therefore, calls for an alternative Air-Conditioner Controller that is durable, efficient, flexible, energy-saving and affordable.

Hence, this paper discusses the Design and Construction of a Cheap Air-Conditional Automation system that schedules automatically when it should be ON or OFF.

\section{Theoretical Background}

HVAC or HACR system design - whose goal is to provide thermal comfort and acceptable indoor air quality - is a combination of some sub-disciplines of Physics, based on the principles of Thermodynamics, Fluid Mechanics and Heat Transfer (Radiation and Convection).

\section{Materials and Methods}

In this work the modular approach - where the overall design was first broken into functional block diagrams- was employed and each block represents a functional section of the circuit that performs a specific function, as shown in figure 1. below and depicts the interconnection between these blocks [11]. For this project, materials were selected according to the requirements of each stage of the design block diagram.

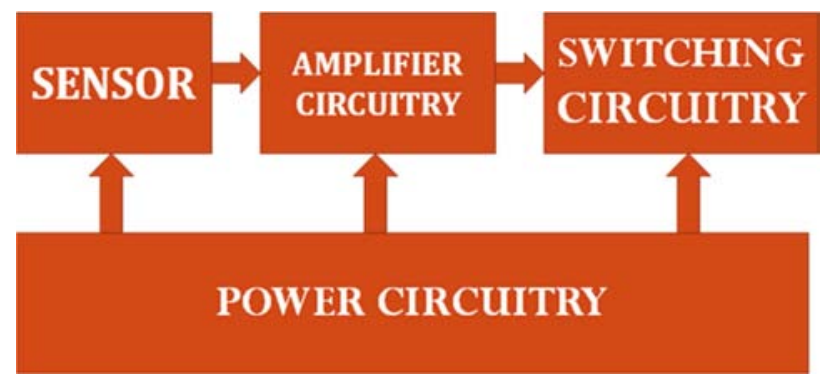

Figure 1. Block Diagram.

\subsection{Sensor}

To sense temperature, sensors are used. A sensor is a device that measures a physical quantity and converts it into a signal/output which can be read by an observer or by an instrument or other part of a system, analogous to a mercury thermometer converts the measured temperature into expansion and contraction of a liquid which can be read on a calibrated glass tube. Temperature monitoring is the process of observing or recording temperature of a system over defined period of time.

The designing of this system begins with the selection of proper sensors for monitoring temperature and other electronic equipments required, among which are the renowned 3-Pin precision Integrated Circuit (IC) Temperature Sensor LM35 (IC1) (figure 2) which was chosen for its sensitivity, accuracy and linearity. Linearity defines how well over a range of temperature a sensor's output consistently changes. Linearity of this precision IC Sensor is very good to $0.5^{\circ} \mathrm{C}$ accuracy and has wide temperature range. Its output voltage is linearly proportional to the Celsius (Centigrade) temperature scale. It operates from 4 to 30 volts. Output of the IC1 is $10 \mathrm{mv} /$ degree centigrade. 


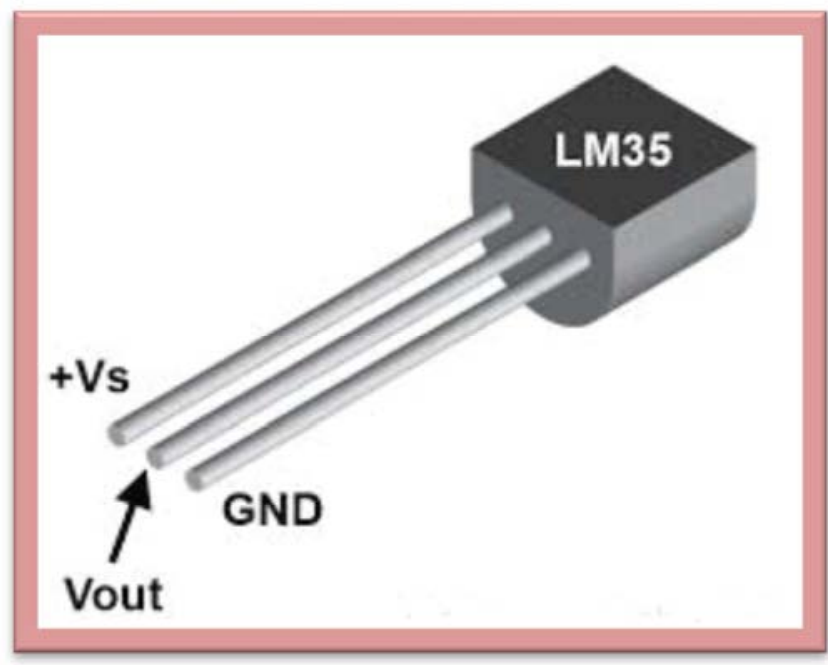

Figure 2. LM35 (IC 1).

\subsection{Amplifier}

The amplifying section of this system receives the output from the sensor stage and improves on it, that is, strengthens it (amplify) to a level strong enough to energies the switching stage of the system. In this stage, a general purpose OP-AMP Integrated Circuit (IC) was required.

An Operational Amplifier, or op-amp for short, is fundamentally a voltage amplifying device designed to be used with external feedback components such as resistors and capacitors between its output and input terminals. An Operational Amplifier is basically a three-terminal device which consists of two high impedance inputs, one called the Inverting Input, marked with a negative or "minus" sign, (-) and the other one called the Non-inverting Input, marked with a positive or "plus" sign $(+)$ [12]. The OP AMP is a 'Linear Amplifier' with an amazing variety of uses. Its main purpose is to amplify (increase) a weak signal - a little like a Darlington Pair [13]. Hence, the choice of general purpose OP-AMP IC - Op-amp 741- which was selected for its versatility, availability and affordability.

The LM35 with this popular Op-amp 741 (IC 2) (figure. 3 below), wired as an inverting amplifier, is used to sense the status of the temperature sensor IC1 which also controls a Relay Driver that serves as the actuator that turns the $\mathrm{AC}$ on or off as instructed by the control circuit as depicted by figure 1 above.

Normally, when the temperature is above a set value (trigger) voltage on pin 2 of IC 2 which is set by using preset or potentiometer. So, the comparator output (at pin 6) of IC 2 goes high and the relay driver triggered the relay to supply mains power to the AC. Conversely, when the temperature is the below trigger voltage, comparator output goes low, thereby, de-energiesing the switching circuitry and disconnecting the $\mathrm{AC}$ from power.

Discussion on power supply to the circuits is omitted as it could be operated off the mains supply using a standard ac mains adaptor $(100 \mathrm{~mA}$ at $9 \mathrm{~V})$ or using a traditional capacitive voltage divider assembly.

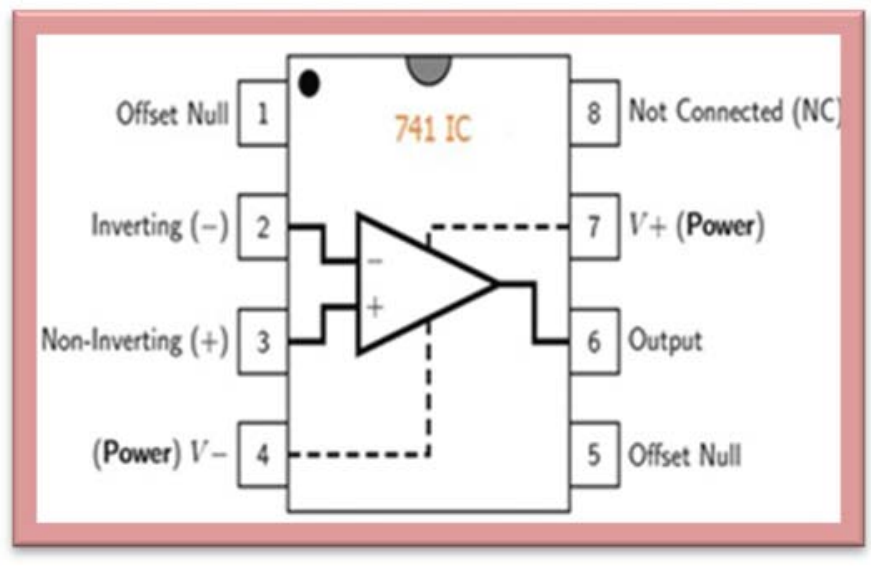

Figure 3. IC 741 (IC2).

\section{Results}

The system was constructed according to the diagrams above and was tested by exposing the sensor to a source of heat thereby increasing its surrounding temperature above a predetermined level, at this instance the AC automatically switched on and remained at this state as long as heat source was present. The source of heat was later withdrawn and this resulted in the AC switching off automatically after some times. These signified changes in the surrounding temperature and the system's ability to switch ON or OFF $\mathrm{AC}$ automatically.

\section{Discussion}

Thus far, it has been shown; from the results; that the constructed system was able to schedules automatically when it should be ON or OFF based on the prevailing ambient temperature thereby making life and living convenient for people by making switching AC convenient for home owners/occupants by eliminating manual switching and at the same time improving his/her comfort with an added advantage of its ability to conserve energy.

\section{Conclusions}

In conclusion, however, the aim of this project which was to design and construct a Cheap AC Automation system was achieved. The system was an impressible product that can replace the old fashioned-manual- method of activating and deactivating $\mathrm{AC}$ and a cheaper alternative to the highly expensive ones. The system can be used for both indoor and outdoor cooling system. It is a very sensitive system/device that is always ready to switch an AC on or off depending on the prevailing temperature of the surroundings. The uniqueness of this project is that, it is sensitive, portable, durable, efficient, flexible and energy-saving. These make it stand out and it is affordable.

Hence, the Cheap AC Automation system is capable of scheduling automatically when it should be ON or OFF. 


\section{Acknowledgements}

I want to appreciate: The reviewers for their times, efforts and candid reviews of this paper, Judy Garland - Editorial assistant of Science Publishing Group (SPG) - for his efforts at making sure that the paper is published at a discount and above all to SPG, USA for granting the opportunity to publish in their Journal. Thank you all.

\section{References}

[1] Home Automation \& Wiring (1st ed.). New York: McGrawHill/TAB Electronics. 1999-03-31. ISBN 9780070246744.

[2] Marimuthu, R., Singh, A. K., Balamurugan, S., \& Aroul, K. (2006). Home Automation Using Bluetooth-A Review

[3] Piyare, R., \& Tazil, M. (2011, June). Bluetooth based home automation system using cell phone. In Consumer Electronics (ISCE), 2011 IEEE 15th International Symposium on (pp. 192-195). IEEE.

[4] Naresh, D., Chakradhar, B., \& Krishnaveni, S. (2013). Bluetooth Based Home Automation and Security System Using ARM9. International Journal of Engineering Trends and Technology (IJETT)-Volume, 4, 4052.

[5] Rana, M., \& Singh, R. (2014). "Smart Homes for a better living using Bluetooth communication based on ATmega Microcontroller". International Journal of Research in Engineering and Technology, 3(6), 210-213.

[6] Pandya, B., Mehta, M., \& Jain, N. (2016). Android Based Home Automation System Using Bluetooth \& Voice Command.

[7] Preville, Cherie (26 Aug 2013). "Control Your Castle: The Latest in HVAC Home Automation". ACHRNews. ACHRNews. Retrieved 15 Jun 2015.

[8] Berger, Lars T.; Schwager, Andreas; Pagani, Pascal; Schneider, Daniel M. (February 2014). Smart Grid
Applications, Communications, and Security. Devices, Circuits, and Systems. CRC Press. ISBN 9781466557529.

[9] "Tips: Smart Appliances | Department of Energy". energy. gov. Retrieved 2016-04-20.

[10] "Home Automation in the Wild: Challenges and Opportunities". Retrieved 2016-04-20.

[11] K. Akinloye Oyelakin, Design and Construction of a WorldWide-Mobile-Call-Back Burglar Alarm System, International Journal of Innovation and Scientific Research, Vol. 12 No. 1 Nov. 2014, pp. 65-69.

[12] “Operational Amplifier Basics". http://www.electronicstutorials.ws/opamp/opamp_1.html.Retrieved 2017-04-21.

[13] "The 741 Operational Amplifier". http://www.technologystudent.com/elec1/opamp1.htm.Retriev ed 2017-04-21.

[14] Electronics Workbench Software, Version 5.12, 2005.

\section{Biography}

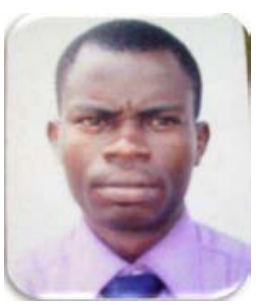

Oyelakin Kazeem Akinloye, received his Master of Technology (M. Tech) from The Federal University of Technology (FUT) Akure, Nigeria in 2014 and a Postgraduate Diploma in Physics and Electronics, from the same University, in 2006 having obtained his undergraduate - in 2002 - in the same field. A member of academics of Rufus Giwa Polytechnic, Owo, Nigeria, whose fields of interest span Instrumentation, Electronic Projects, Space/Environmental Studies, Security, swarm intelligence and Physics as a whole, he has published research papers in Refereed International Journals. And, he belongs to the Space Research Group of Federal University of Technology, Akure, Ondo State, Nigeria. 